\title{
Facilitative effects of shock on bar-pressing
}

ALAN R. MILLER, ROBERT A. STEWART, RICHARD A. R. WATSON, and VERNON L. KIKER, Analytic Behavioral Systems, ${ }^{1}$ Pasadena, Calif. 91103 and Stanford Unilersity, Stanford, Calif. 94305

Eight male rats were divided into two groups and run under two conditions. Group $l$ (NS) normal lab environment without shock; Group 2 (S) normal lab environment with gradually increasing shock intensity. It was predicted that a decrease in responding would occur for the shock group, but responding would recover to reach a higher level. It was also predicted that, after recovery, when noncontingent food was presented to Group 2, Ss would bar-press for shock alone due to their increased arousal requirements. The results of this study substantiate our predictions.

During the last decade psychologists and biologists have been trying to specify the dynamics of how arousal and tonic output are related to sensory input. In the writings of Selye (1952), Hebb (1955), and Berlyne (1960) we find this new sense of the complexity of the topic. Quite apart from the theoretical analysts in the field specific experiments relating arousal, behavior, and sensory input have been performed. For example, Harrington \& Linder (1962), and Harrington \& Kohler $(1966 a, b)$ found that shock as well as light reinforced barpressing. The above studies were substantiated under severe conditions of sensory deprivation (Miller, Kiker, \& Stewart, 1967; Miller, Stewart, \& Kiker, 1968). In these later experiments rats lived in a constantly deprived environment, and maintained themselves totally by pressing a bar which delivered food and shock. Shock was increased by $.05 \mathrm{~mA}$ until the final shock level was $1.03 \mathrm{~mA}$. The results indicated that Ss bar-pressed more when sensory deprived and shocked during self-maintenance and extinction.
In order to define the problem more accurately it was necessary to specify the level of shock which was noxious under normal lab conditions. Stewart, Miller, \& Kiker (1967) and Stewart \& Kiker (1968) found that $.45 \mathrm{~mA}$ of shock would eliminate approach responses in a runway. Likewise, Stewart \& Miller $(1967)^{2}$ found that $.75-\mathrm{mA}$ shock eliminated operant responding in a Skinner box. These levels were below the $1.03 \mathrm{~mA}$ used above. This would imply (taking into account adaptation procedures) that shock after initial adaptation is a positive reinforcer, until a point where it becomes noxious. At this point, with continued exposure, a change in arousal requirement may occur and shock again becomes a positive reinforcing agent.

Berlyne (1960) and others have pointed out that changes in arousal requirements may have lasting effects on the $\mathrm{S}$. For example, sensory deprivation studies demonstrate that GSR and EEG patterns still remain disturbed and unstable for a number of days after the experience.

In the present study our concern is with two "moments" in particular: (a) The moment of the change in arousal requirement where the reinforcing process seems to "sag" and then recover, and (2) the moment when noncontingent food is presented and the bar remains electrified. It is predicted that a "dip" in responding would occur for the shock group and that responding would recover to a new high, and that when noncontingent food is presented Ss would bar-press for shock alone to fulfill their modified arousal requirements.

\section{METHOD}

Eight 85-day-old male Sprague-Dawley rats were matched for bar-presses and assigned to two groups. Group 1, the nonshock (NS) group, bar-pressed for food but was never shocked. Group 2, the shocked group (S), received food and shock on every bar-press. Both groups were given "free" water

OPERANT RATE AS A FUNCTION OF SHOCK INTENSITY

PART I--- FEEDER ON

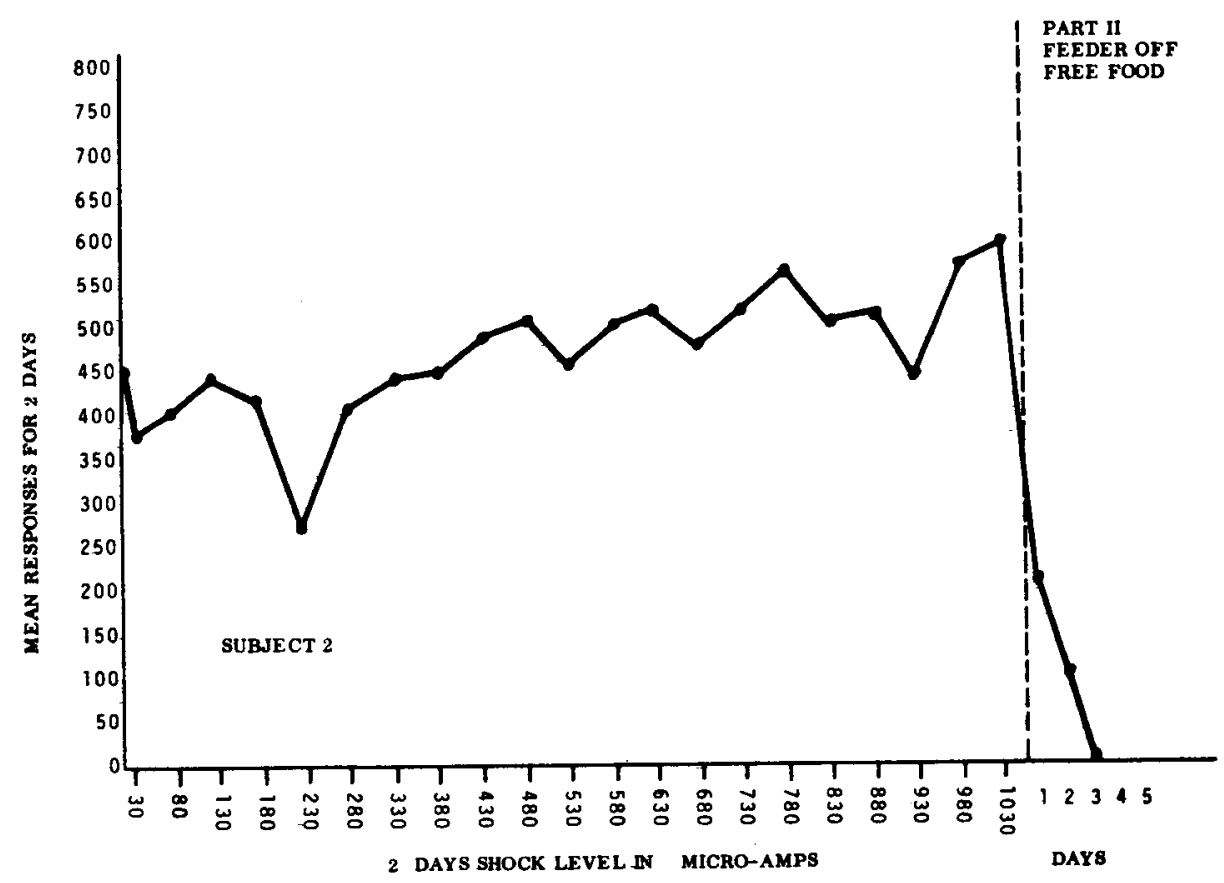




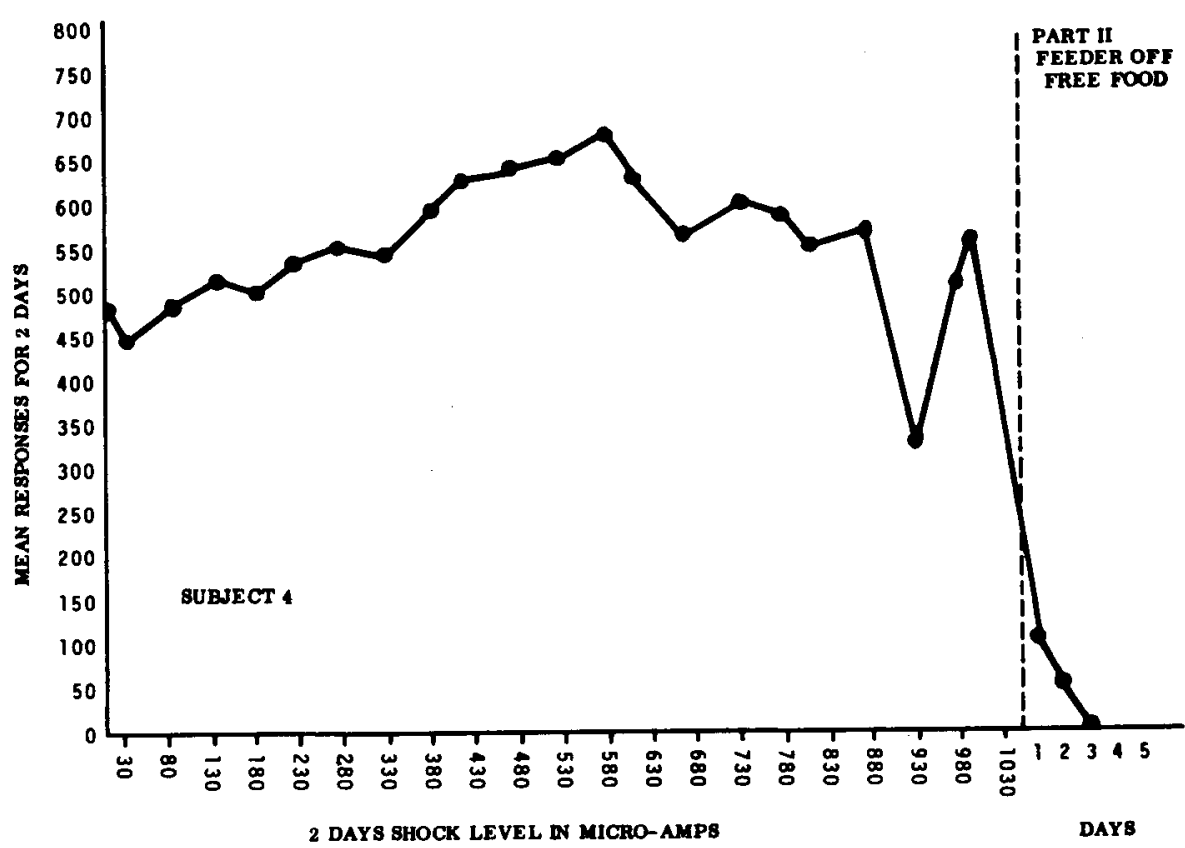

but obtained their entire food supply by barpressing in Lucite non-sound-proof Skinner boxes. Shock was delivered to Group 2 (S) by a constant current shock source which when the bar was pressed would close the circuit between the cage floor and the bar. Shock (initial level $=.03 \mathrm{~mA}$ ) was increased by $.05 \mathrm{~mA}$ every two days until the final level of shock was $1.03 \mathrm{~mA}$. Random meter checks were made to insure that no $\mathrm{S}$ had learned to avoid the shock. On the 45 th day both groups received noncontingent food, the feeders were shut off, and the shock circuit remained connected for Group 2 (S).

\section{RESULTS}

All Ss in Group 2 (S) showed the predicted "dip" in rate of responding at some time during the food contingent shocked trials. Rate of responding curves for two Ss are presented in Fig. 1. Each point represents the average rate of responding for two days at each shock level. The mean rate of responding on the final two days of shock exceeded the "dip" scores and was significant $(t=12.14, \mathrm{df}=3, \mathrm{p}=.005)$. The average number of responses on the final two days for Group 2 (S) was significantly different from Group 1 (NS) $(t=7.52, \mathrm{df}=6$, $\mathrm{p}=.001)$.

The mean number of responses for Group 1 (NS) during the first $24 \mathrm{~h}$ of the noncontingent food period was 43 , while the mean for Group 2 (S) was 164. The difference was significant $(t=3.85, d f=6, p=.005)$. Although there was no statistical difference in the amount of food the two groups consumed during the noncontingent period Group 2 (S) did eat more.

\section{DISCUSSION}

The results indicate that arousal requirements can be modified as demonstrated by the "dip" and recovery, and by the greater number of responses in Group 2 (S) in the noncontingent food section. Since this occurred it would be interesting to speculate on the number of steps involved in this process.

The experiment, as summarized by the graphs, indicates a specific "syndrome" of adaptation to shock intensity: (1) An approach pattern is established by food reinforcement. (2) An initial avoidance response is instigated by introducing a novel stimulus. (3) Shock becomes a positive reinforcing agent. (4) A point of stimulus intensity is reached where it becomes noxious. (5) Adaptation occurs again since food is contingent upon a shocked response. Barpresses increase as if the animal had previously been "holding" back. (6) Another change in arousal requirement could later occur, although not clearly indicated by this study. (7) Final shock level is reached where the animal is no longer able to adapt or change his arousal requirements.

\section{REFERENCES}

BERLYNE, D. E. Conflict, arousal, and curiosity. New York: McGraw-Hill, 1960.

HARRINGTON, G. M. \& LINDER, W, K. A positive reinforcing effects of electrical stimulation. Journal of Comparative \& Physiological Psychology, 1962, 66, 1014-1015.

HARRINGTON, G. M., \& KOHLER, G. R. Sensory deprivation and sensory reinforcement with shock. Psychological Reports, 1966a, 18, 802-808.

HARRINGTON, G. M., \& KOHLER, G. R. Strain differences and positive reinforcement with shock. Psychonomic Science, 1966b, 6, $419-420$.

HEBB, D. O. Drives and the C.N.S. (conceptual nervous system). Psychological Review, 1955, 62, 243-254.

MILLER, A. R., KIKER, V. L., \& STEWART, R. A. A technique for studying the relationship between shock and bar-presses. Paper read at the Western Psychological Association, May, 1967, San Francisco, Calif.

MILLER, A. R., STEWART, R. A., \& KIKER, V. L. The facilitative effects of shock and sensory deprivation on bar-pressing during extinction. Psychonomic Science, 1968, 10, 113-114.

SELYE, $H$. The story of the adaptation syndrome. Montreal: Acta, 1952.

STEWART, R. A., MILLER, A. R., \& KIKER, V. L. General drive level as a function of conflict. Paper read at the Western Psychological Association, May, 1967, San Francisco, Calif.

STEWART, R. A., KIKER, V. L. The effect of conflict on delayed response performance. Paper read at the Western Psychological Association, 1968, San Diego, Calif.

NOTES

1. Requests for reprints should be directed to Analytic Behavioral Systems, Box 3085, Pasadena, Calif. 91103.

2. Unpublished study. California State College at Los Angeles. 